\title{
Seroepidemiology of Toxoplasma gondii Among Pregnant Women Attending Antenatal Care in Northwest Ethiopia
}

This article was published in the following Dove Press journal: Infection and Drug Resistance

Biyansa Adugna'

Zewdu Seyoum Tarekegn (iD) ${ }^{2}$

Debasu Damtie (iD) ${ }^{3,4}$

Seleshe Nigatu Woldegebreal ${ }^{5}$

RP Raju ${ }^{3}$

Moges Maru ${ }^{2}$

Abrham Ayele ${ }^{2}$

'College of Veterinary Medicine, Semera University, Semera, Ethiopia;

${ }^{2}$ Department of Veterinary Paraclinical Studies, College of Veterinary Medicine and Animal Sciences, University of Gondar, Gondar, Ethiopia; ${ }^{3}$ Department of Immunology and Molecular Biology, College of Medicine and Health Sciences, University of Gondar, Gondar, Ethiopia; ${ }^{4}$ The Ohio State University Global One Health LLC, Eastern Africa Regional Office, Addis Ababa, Ethiopia;

${ }^{5}$ Department of Veterinary Epidemiology and Public Health, College of Veterinary Medicine and Animal Sciences, University of Gondar, Gondar, Ethiopia
Correspondence: Zewdu Seyoum Tarekegn

Email zewdu.seyoum@uog.edu.et
Introduction: Toxoplasmosis is a life-threatening disease in pregnant women, having social and economic impacts due to congenital toxoplasmosis. However, in Ethiopia, it is neglected zoonotic disease, which requires screening and identifying risk factors in pregnant women to plan a public health intervention.

Methods: This institutional-based cross-sectional study was employed from March to April 2019 to estimate the seropositivity and assess potential risk factors for T. gondii among pregnant women attending antenatal care in four public hospitals in Northwest Ethiopia. Four hundred and one pregnant women were recruited to collect serum samples. Toxoplasma gondii antibodies were tested using Toxo-Latex slide agglutination test.

Results: Thus, the overall seropositivity for T. gondii was found 70.8\% (95\% CI: $66.3--$ 75.5). Multivariable logistic regression analysis showed that the average monthly income, occupational status, habits of handwashing practices after handling raw meat, water sources for drinking and agroclimatic situations revealed significant $(p<0.05)$ effects on seropositivity for $T$. gondii in pregnant women.

Conclusion: This survey showed high seropositivity for $T$. gondii among pregnant women in Northwest Ethiopia. Therefore, further studies on bioassay, isolation and genotype of the pathogen are crucial. It also requires action to prevent and control the infection with $T$. gondii in pregnant women, which poses a potential threat to a foetus.

Keywords: Northwest Ethiopia, pregnant women, risk factors, seropositivity, T. gondii

\section{Introduction}

Toxoplasma gondii is important obligate intracellular coccidian that infects virtually all warm-blooded mammals and birds. It has been documented that the pathogen affects approximately $30 \%$ of the world human population. ${ }^{1-3}$ Food animals with infected tissue cysts are well-known sources of human infection. Humans and animals can acquire the pathogen via three main pathways: ingesting undercooked meat harbouring the tissue cysts of $T$. gondii or ingesting contaminated water and food with oocysts from the environment and congenital transmission from an affected mother to the foetus during pregnancy. ${ }^{1,4,5}$ Felids play a key role in the epidemiology of $T$. gondii because they are the only definitive hosts that excrete the viable oocysts in their faeces. ${ }^{1,3}$ Felids become infected with $T$. gondii by eating infected tissues from intermediate hosts.

The infection in immunocompetent individuals is asymptomatic and results in the chronic persistence of cysts within host tissues. ${ }^{1,3}$ But, in immunocompromised patients (such as cancer and HIV/AIDS patients); it causes life-threatening encephalitis 
due to the rupture of pre-existent cysts that reactivate latent infections. ${ }^{6,7}$ Moreover, the infection of pregnant women results in miscarriage or congenital infection that causes hydrocephalus, blindness, foetal death, neurological damage/intracranial calcification and retinochoroiditis., $3,8,9$ Recent reports have also reported that toxoplasmosis is a possible risk factor for personality shifts and increased likelihood of reduced intelligence or schizophrenia. ${ }^{10}$ Hence, early serological screening for toxoplasmosis in pregnant women is imperative. ${ }^{9}$

The prevalence of $T$. gondii infection in humans varies with the social and cultural habits of the community, geographical factors, cat lifestyle and density, wildlife structure, climate conditions and mode of transmission. ${ }^{4}$ Globally, the seroprevalence of $T$. gondii infection in humans ranges from $2 \%$ to $100 \%$, depending on the source of the sample. ${ }^{4}$ In Ethiopia, seroprevalence estimates of 18.5-93.3\% have been reported in different risk groups of the population. ${ }^{11-18}$ Similarly, in food animals, serological surveys indicate a high prevalence of Toxoplasma infections, ${ }^{19,20}$ and viable T. gondii isolates were also confirmed from tissues of food animals. $^{21}$ Despite its high animal and public health significance, the wide practice of raw meat consumption, the keeping of cat as pet animals, presence of stray cats and suitable climatic conditions maintaining the survival of the pathogen, information on the seropositivity and associated risk factors of Toxoplasma gondii infection among pregnant women is still limited in the Northwest Ethiopia ${ }^{14,15,22}$ though there are several reports concentrated in the central and southern part of the country. ${ }^{11,16,18,23-25}$ Besides, though the parasite (T. gondii) is responsible for congenital infection resulting in abortion/still birth and neurological complications, no serological screening program during pregnancy in the country has been practiced. Therefore, this study aimed at estimating the seropositivity for $T$. gondii among pregnant women attending antenatal care and identifying possible risk factors associated with $T$. gondii infection in Northwest Ethiopia. The findings of this study would provide baseline information about the seropositivity rate and risk factors of T. gondii in pregnant women and also for planning and implementation of $T$. gondii antenatal screening, control and prevention strategies.

\section{Materials and Methods}

\section{Study Areas}

The study was conducted on pregnant women attending an antenatal care in the University of Gondar (located at
Gondar City), Kolladiba (Dembia district), Ambageorgis (Wogera district) and Addis-Zemen (Libokemkem district) hospitals located in Northwest Ethiopia. Gondar city is located $742 \mathrm{~km}$ far from Addis Ababa, capital city of Ethiopia. Its altitude is $2220 \mathrm{~m}$ above sea level (m.a.s.l). The rainfall pattern is bimodal, with an annual average of $1172 \mathrm{~mm}$ and mean annual temperature of $20^{\circ} \mathrm{C}$. Wogera district has an average altitude of 2900 m.a.s.l in the northern highlands of Ethiopia. The rainfall pattern is bimodal, with an annual average of $700 \mathrm{~mm}$ and mean annual temperature of $12.7^{\circ} \mathrm{C}$. Dembia district has an elevation ranges from 1500 to 2500 m.a.s.l and the area is mainly midland. Libokemkem has an average elevation of 2000 m.a.s.l. The rainfall pattern is unimodal, with an annual average of $1300 \mathrm{~mm}$ and a mean annual temperature of $19.7^{\circ} \mathrm{C}$.

\section{Study Design and Population}

This institutional-based cross-sectional study was employed from March to April 2019 in Northwest Ethiopia to estimate seropositivity and assess the risk factors for $T$. gondii in pregnant women who attended the outpatient obstetric clinic. Four hundred and one pregnant women were recruited at the University of Gondar, Kolladiba, Ambageorgis and Addis-Zemen hospitals located in the Amhara regional state, Northwest Ethiopia. Pregnant women who were seriously ill and not consent to participate were excluded from this study.

\section{Blood Sample Collection and Serological Analysis}

Blood samples were collected by trained medical laboratory personnel to have serum for serological analysis for T. gondii. Approximately $5 \mathrm{~mL}$ of the venous blood sample was drawn from each consenting study participant aseptically using a plain tube. Test tubes were labelled properly with the necessary information. Then, the whole blood was left for an hour at room temperature to allow clotting and then centrifuged at $3000 \mathrm{rpm}$ for $10 \mathrm{~min}$ to separate serum. The serum was collected using $1.5-\mathrm{mL}$ Eppendorf serum tubes and then, transported using an icebox to the Parasitology Laboratory, College of Veterinary Medicine and Animal Sciences, University of Gondar. The serum samples were kept at $-20^{\circ} \mathrm{C}$ until the serological test was made using a commercial Toxo-Latex agglutination test (SPINREACT, S.A/S.A.U Ctra Santa Coloma, Spain) following the manufacturer's instructions. 


\section{Questionnaire Survey}

A structured and pre-tested questionnaire was also used to gather information on sociodemographic characteristics, environmental, obstetrical/clinical and behavioural factors anticipated to be associated with $T$. gondii seropositivity in the study participants to get relevant information. The exit interview with the participants was made to gather the required data. The questionnaire was administered by trained health professionals.

\section{Data Management and Analysis}

The collected data using a questionnaire and laboratory analysis were stored in EPI Info version 7 and analysed using SPSS version 20.0. Descriptive statistics were used to summarize the result concerning the risk factors. The seropositivity rate was calculated as the number of seropositive serum samples divided by the total number of serum samples tested. Logistic regression was employed to identify the risk factors associated with $T$. gondii seropositivity. The independent variables with a p-value of $\leq 0.20$ during the univariable logistic analysis were fitted into a multivariable logistic regression model to avoid the effect of confounders. Adjusted Odds Ratio (AOR) with the corresponding $95 \%$ confidence interval (CI) was estimated to show the strength of the association. A $P$-value $<0.05$ was used to declare statistically significant in the final model. The model fitness was checked using the Hosmer-Lemeshow goodness-of-fit test.

\section{Ethical Considerations}

The study was performed in accordance with good clinical practices following the principle of the declaration of Helsinki. ${ }^{26}$ Ethical clearance was received from the University of Gondar Ethics Committee (Ref. No: V/P/ RCS/05/1237/2018). All volunteer study participants were informed about the study and written agreements were obtained from all involved women. Confidentiality was assured using codes.

\section{Results}

\section{Characteristics of Study Participants}

A total of 401 pregnant women aged between 18 and 46 years with a mean age of $26.8 \pm 5.08$ years attending ANC clinics at Addis-Zemen, Ambageorgis, Dembia, and University of Gondar hospitals were recruited and involved in this study. Nearly half of the study participants (53.1\%) were found within the age group of 25-30 years while $17 \%$ of them had more than 30 years of age. The majority (55.6\%) of them were urban residents and 38.9\% of them were unable to read and write. According to gestational age, 84 (20.9\%), $169(42.1 \%)$ and 148 $(36.9 \%)$ were at the first, second and third trimester, respectively. Approximately $32.2 \%$ of the participants were housewives followed by governmental employees (24.7\%), farmers $(22.9 \%)$ and self-employed (traders) (20.2\%). Half of the study participants had an average monthly income of 3001-6000 Ethiopian birr. Fortyseven percent of the study participants owned a cat in their home. The seropositivity for $T$. gondii and other demographic characteristics of the study participants is indicated in Table 1.

\section{Toxoplasma gondii Seropositivity and Its Associated Risk Factors}

In this survey, the overall seropositivity for $T$. gondii antibodies among pregnant women was found $70.8 \%(95 \%$ CI: $66.3 \%-75.5 \%)$. T. gondii seropositivity was found to be higher among pregnant women from Dembia primary hospital (78\%) followed by Addis-Zemen primary hospital (75\%), Gondar comprehensive specialized hospital (68\%) and Ambageorgis primary hospital (54.2\%) as indicated in Figure 1.

Of the study pregnant women; $29.9 \%$ were between age groups of $18-24$ years, $53.1 \%$ were between 25 and 30 years and $17 \%$ were over 30 years. The seropositivity of T. gondii among age groups $18-24,25-30$ and over 30 years was found to be $70 \%, 72 \%, 69 \%$, respectively. However, no significant association was observed between seropositivity and age. There was no significant association between seropositivity for $T$. gondii and educational level and residence of the participant (Table 2).

None of the study participants had a history of organ transplantation; whereas $7 \%$ had a history of blood transfusion in their lifetime. Of those who had blood transfusion history, $86 \%$ were seropositive. From the participants, $19.2 \%$ had an abortion history of whom $75 \%$ were seropositive. From the study of pregnant women, 47.1\% reported having a domestic cat at home. Of them, the seropositivity was found to be $69 \%$ (Table 3 ).

Assessment of raw meat eating habits revealed only a minority (23.2\%) experienced eating raw meat; $76.8 \%$ had no experience of raw meat eating habits throughout their lifetime. Among those who had a raw meat-eating habit, the seropositivity for T. gondii was $73 \%$. Similarly, 
Table I Demographic Characteristics of Pregnant Women Attending ANC at Selected Hospitals, Northwest Ethiopia

\begin{tabular}{|c|c|c|c|c|}
\hline \multirow[t]{2}{*}{ Variables } & \multirow[t]{2}{*}{ Categories } & \multicolumn{2}{|c|}{ Seroprevalence } & \multirow[t]{2}{*}{ Total n (\%) } \\
\hline & & Negative $n$ (\%) & Positive n (\%) & \\
\hline \multirow[t]{3}{*}{ Age (Years) } & $18-24$ & $36(30)$ & $84(70)$ & $120(29.9)$ \\
\hline & $25-30$ & $60(28)$ & $153(72)$ & $213(53.1)$ \\
\hline & $>30$ & $2 I(3 I)$ & $47(69)$ & $68(17)$ \\
\hline \multirow[t]{2}{*}{ Residential } & Rural & $56(3 I)$ & $122(69)$ & $178(44.4)$ \\
\hline & Urban & $61(27)$ & $162(73)$ & $223(55.6)$ \\
\hline \multirow[t]{4}{*}{ Educational level } & Illiterate & $48(3 I)$ & $108(69)$ & $156(38.9)$ \\
\hline & Primary & $16(25)$ & $49(75)$ & $65(16.2)$ \\
\hline & Secondary & $20(26)$ & $58(74)$ & $78(19.5)$ \\
\hline & Above secondary & $33(32)$ & $69(68)$ & $102(25.4)$ \\
\hline \multirow[t]{4}{*}{ Occupational status } & Governmental employee & $36(36)$ & $63(64)$ & $99(24.7)$ \\
\hline & Traders (self-employed) & $16(20)$ & $65(80)$ & $81(20.2)$ \\
\hline & Farmers & $30(33)$ & $62(67)$ & $92(22.9)$ \\
\hline & Housewives & $35(27)$ & $94(73)$ & $129(32.2)$ \\
\hline \multirow[t]{3}{*}{ Gestational period } & Ist trimester & $23(27)$ & $61(73)$ & $84(20.9)$ \\
\hline & 2nd trimester & $52(3 I)$ & 117 (69) & $169(42.1)$ \\
\hline & 3rd trimester & $42(28)$ & $106(72)$ & $148(36.9)$ \\
\hline \multirow[t]{4}{*}{ Average monthly income (ETB) } & $<1000$ & $35(31.5)$ & $76(68.5)$ & III (27.7) \\
\hline & $1000-3000$ & $53(26)$ & $149(74)$ & $202(50.4)$ \\
\hline & $300 \mathrm{I}-6000$ & $19(28)$ & $49(72)$ & $68(17)$ \\
\hline & $\geq 6001$ & $10(50)$ & $10(50)$ & $20(5)$ \\
\hline
\end{tabular}

$37.2 \%$ experienced eating uncooked vegetables. The seropositivity for Toxoplasma among those who experienced raw vegetable eating habit was $75 \%$ (Table 3 ).

Risk factor analysis was conducted using univariate and multivariate logistic regression. The results of univariate logistic regression analysis demonstrated that occupational status, average monthly income (in ETB), history of blood transfusion, hand washing practice after handling raw meat, the habit of raw vegetable consumption, residence agroecology (Figure 2) and sources of drinking water had a $p$-value $<0.2$. These variables were considered for further analysis using multivariate logistic

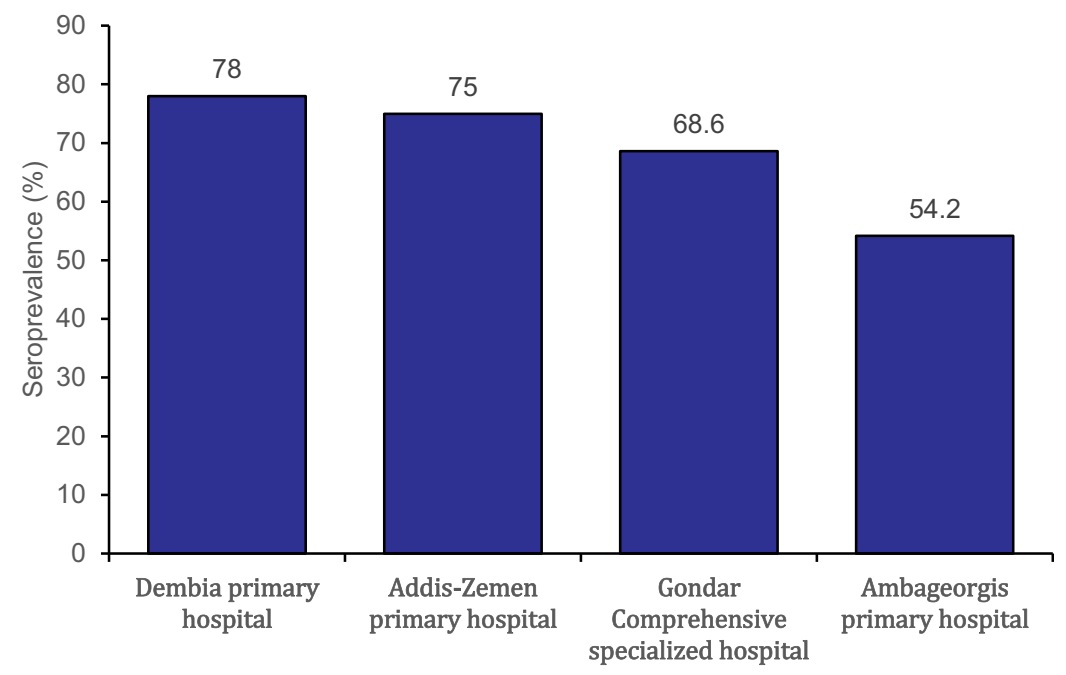

Figure I Seropositivity for T. gondii in pregnant women among health facilities. 
Table 2 Demographic Risk Factors Associated with T. gondii Seropositivity in Pregnant Women

\begin{tabular}{|c|c|c|c|c|c|}
\hline Variables & Category & Total n (\%) & Seropositive n (\%) & COR $(95 \% \mathrm{Cl})$ & AOR $(95 \% \mathrm{Cl})$ \\
\hline \multirow[t]{3}{*}{ Age (years) } & $18-24$ & $120(29.9)$ & $84(70)$ & 1.00 & \\
\hline & $25-30$ & $213(53.1)$ & $153(72)$ & $1.09(0.67-1.79)$ & - \\
\hline & $>30$ & $68(17)$ & $47(69)$ & $0.96(0.50-1.83)$ & - \\
\hline \multirow[t]{2}{*}{ Residence } & Rural & 178 (44.4) & $122(69)$ & 1.00 & \\
\hline & Urban & $223(55.6)$ & $162(73)$ & $1.22(0.79-1.88)$ & - \\
\hline \multirow[t]{4}{*}{ Educational status } & Illiterate & $156(38.9)$ & $108(69)$ & $1.08(0.63-1.84)$ & - \\
\hline & Primary & $65(16.2)$ & $49(75)$ & $1.47(0.73-2.95)$ & - \\
\hline & Secondary & $78(19.5)$ & $58(74)$ & $1.39(0.72-2.67)$ & - \\
\hline & Above secondary & $102(25.4)$ & $69(68)$ & 1.00 & \\
\hline \multirow[t]{4}{*}{ Occupation } & Farmers & $94(23.4)$ & $59(63)$ & 1.00 & 1.00 \\
\hline & Traders & $102(25.4)$ & $82(80)$ & $2.43(1.28-4.63)^{*}$ & $2.69(1.28-5.63)^{* *}$ \\
\hline & Governmental employee & $92(22.9)$ & $62(67)$ & $1.23(0.67-2.24)$ & $1.33(0.6 \mathrm{I}-2.9 \mathrm{I})$ \\
\hline & Housewife & $113(28.2)$ & 81 (72) & $1.50(0.84-2.70)^{*}$ & $1.49(0.80-2.80)$ \\
\hline \multirow[t]{4}{*}{ AMI (ETB) } & $<1000$ & III (27.7) & $76(69)$ & $2.17(0.83-5.69)^{*}$ & $3.57(1.19-10.64)^{* *}$ \\
\hline & $1000-3000$ & $202(50.4)$ & $149(74)$ & $2.81(1.11-7.13)^{*}$ & $3.81(1.37-10.61)^{* *}$ \\
\hline & $300 I-6000$ & $68(17)$ & $49(72)$ & $2.58(0.93-7.18)^{*}$ & $3.88(1.27-1 \mathrm{I} .84)^{* *}$ \\
\hline & $\geq 6001$ & $20(5)$ & $10(50)$ & 1.00 & 1.00 \\
\hline
\end{tabular}

Notes: *p-value $<0.2$, **p-value $<0.05$.

Abbreviation: AMI, average monthly income.

regression analysis. Thus, occupational status, average monthly income of household (ETB), the residence agroecology, the habit of handwashing practices after handling raw meat and sources of drinking water were significantly associated with seropositivity for $T$. gondii ( $p$-value $<0.05$ ). Accordingly, self-employed study participants (traders) $(\mathrm{AOR}=2.53,95 \% \mathrm{CI}: 1.17-5.50, p=0.019)$; participants having an average monthly income of $<1000$ $(\mathrm{AOR}=3.57,95 \%$ CI: 1.19-10.64, $p=0.023)$, 1000-3000 $(\mathrm{AOR}=3.81,95 \%$ CI: $1.37-10.61, p=$ $0.010)$ and 3001-6000 (ETB) (AOR $=3.88$, 95 CI: $1.27--$ $11.84, p=0.017)$; irregular handwashing practices after handling raw meat $(\mathrm{AOR}=1.93,95 \% \mathrm{CI}: 1.06-3.53, p=$ $0.031)$; midland climatic condition $(\mathrm{AOR}=2.16,95 \mathrm{CI}$ : $1.23-3.63, p=0.007)$ and unprotected well/spring water sources used for drinking (AOR $=2.37,95 \%$ CI: $1.03-$ 5.43, $p=0.042$ ) were found to be the main predictors associated with $T$. gondii seropositivity among ANC attended pregnant women in selected hospitals located in Northwest Ethiopia (Table 3).

\section{Discussion}

Estimating of $T$. gondii seropositivity in pregnant women has a paramount significance because of the risk of infection of the foetus or new-born and reactivation of infection in immunocompromised individuals. This study revealed overall seropositivity of $70.8 \%$ for $T$. gondii among ANC attending pregnant women in Northwest Ethiopia. Although the prevalence in this study is lower than the previous studies in Ethiopia, ${ }^{12,16,23,24}$ it has been noted that different serological tests and cut-off values were used so it is difficult to compare the studies. Alternatively, this study reported higher seropositivity than studies conducted elsewhere in the world. ${ }^{25,27-29}$ The variation in seropositivity might be due to variation in the geographical distribution of the parasite, climatic condition (dry or moist climate, temperature and relative humidity), cat population densities and feeding habits, the cultural pattern of the population (feeding habits) and socioeconomic status. ${ }^{3,7}$ It may also be varied due to the prevalence of the parasite in animals and the type of animal consumed. The difference is further attributed to the sampled population, genetic background of the parasite and the host, a type of immune response elicited by the parasite. The serological test method used and sensitivity difference could explain such discrepancies. . $^{15,24,27}$

The current study showed a strong association between the average monthly income of pregnant women and seropositivity for T. gondii. This finding is in agreement with the previous study conducted in Zambia. ${ }^{30}$ In contrast, 
Table 3 Clinical, Behavioural and Environmental Risk Factors Associated with T. gondii Seropositivity in Pregnant Women

\begin{tabular}{|c|c|c|c|c|c|}
\hline Variables & Category & $\begin{array}{l}\text { Total } \\
\text { n (\%) }\end{array}$ & $\begin{array}{c}\text { Seropositive } \\
\text { n (\%) }\end{array}$ & COR $(95 \% \mathrm{Cl})$ & AOR $(95 \% \mathrm{Cl})$ \\
\hline Gestational period & $\begin{array}{l}\text { Ist trimester } \\
\text { 2nd trimester } \\
\text { 3rd trimester }\end{array}$ & $\begin{array}{l}84(20.9) \\
169(42.1) \\
148(36.9)\end{array}$ & $\begin{array}{l}61(73) \\
117(69) \\
106(72)\end{array}$ & $\begin{array}{c}1.18(0.66-2.11) \\
1.00 \\
1.12(0.69-1.82)\end{array}$ & - \\
\hline History of abortion & $\begin{array}{l}\text { No } \\
\text { Yes }\end{array}$ & $\begin{array}{l}324(80.8) \\
77(19.2)\end{array}$ & $\begin{array}{c}226(70) \\
58(75)\end{array}$ & $\begin{array}{c}1.00 \\
1.32(0.75-2.34)\end{array}$ & - \\
\hline Child with visual impairment & $\begin{array}{l}\text { No } \\
\text { Yes }\end{array}$ & $\begin{array}{l}394(98.3) \\
7(1.7)\end{array}$ & $\begin{array}{c}278(7 I) \\
6(86)\end{array}$ & $\begin{array}{c}1.00 \\
2.50(0.3-21.03)\end{array}$ & - \\
\hline History of blood transfusion & $\begin{array}{l}\text { No } \\
\text { Yes }\end{array}$ & $\begin{array}{c}373(93) \\
28(7)\end{array}$ & $\begin{array}{l}260(70) \\
24(86)\end{array}$ & $\begin{array}{c}1.00 \\
2.61(0.88-7.69)^{*}\end{array}$ & $\begin{array}{c}1.00 \\
2.87(0.88-9.30)\end{array}$ \\
\hline Habit of raw meat consumption & $\begin{array}{l}\text { No } \\
\text { Yes }\end{array}$ & $\begin{array}{l}308(76.8) \\
93(23.2)\end{array}$ & $\begin{array}{l}216(70) \\
68(73)\end{array}$ & $\begin{array}{c}1.00 \\
1.16(0.69-1.95)\end{array}$ & - \\
\hline $\begin{array}{l}\text { Handwashing practices after handling raw } \\
\text { meat }\end{array}$ & $\begin{array}{l}\text { Always } \\
\text { Sometimes } \\
\text { Never }\end{array}$ & $\begin{array}{c}288(71.8) \\
102(25.4) \\
11(2.7)\end{array}$ & $\begin{array}{l}198(69) \\
78(76) \\
8(73)\end{array}$ & $\begin{array}{c}1.00 \\
1.48(0.88-2.49)^{*} \\
1.21(0.31-4.68)\end{array}$ & $\begin{array}{c}1.00 \\
1.93(1.06-3.53)^{* *} \\
1.22(0.29-5.16)\end{array}$ \\
\hline Habit of raw vegetable consumption & $\begin{array}{l}\text { No } \\
\text { Yes }\end{array}$ & $\begin{array}{l}252(62.8) \\
149(37.2)\end{array}$ & $\begin{array}{l}172(68) \\
112(75)\end{array}$ & $\begin{array}{c}1.00 \\
1.4 \mid(0.89-2.22)^{*}\end{array}$ & $1.41(0.84-2.37)$ \\
\hline Residence agroclimatic situations & $\begin{array}{l}\text { Highland } \\
\text { Midland } \\
\text { Lowland }\end{array}$ & $\begin{array}{c}75(18.7) \\
285(7 I .1) \\
4 I(10.2)\end{array}$ & $\begin{array}{l}44(59) \\
213(75) \\
27(66)\end{array}$ & $\begin{array}{c}1.00 \\
2.08(1.23-3.55)^{*} \\
1.36(0.62-3.00)\end{array}$ & $\begin{array}{c}1.00 \\
2.16(1.23,3.63)^{* *} \\
1.34(0.59,3.03)\end{array}$ \\
\hline Sources of water & $\begin{array}{l}\text { Hand pump } \\
\text { Municipal pump } \\
\text { Unprotected well } \\
\text { water } \\
\text { Protected well water }\end{array}$ & $\begin{array}{l}203(50.6) \\
106(26.4) \\
62(15.5) \\
30(7.5)\end{array}$ & $\begin{array}{l}137(67) \\
80(75) \\
46(74) \\
21(70)\end{array}$ & $\begin{array}{c}1.00 \\
1.48(0.87-2.52)^{*} \\
1.39(0.73-2.63) \\
1.12(0.49-2.59)\end{array}$ & $\begin{array}{c}1.00 \\
1.16(0.54-2.48) \\
2.37(1.03-5.43)^{* *} \\
1.91(0.66-5.5 \mathrm{I})\end{array}$ \\
\hline Cat presence at home & $\begin{array}{l}\text { No } \\
\text { Yes }\end{array}$ & $\begin{array}{l}212(52.9) \\
189(47.1)\end{array}$ & $\begin{array}{l}154(73) \\
130(69)\end{array}$ & $\begin{array}{c}1.00 \\
0.83(0.54-1.28)\end{array}$ & - \\
\hline
\end{tabular}

Notes: $* p$-value $<0.2,{ }^{* *} p$-value $<0.05$

a study conducted in central Ethiopia showed the absence of a significant association between average monthly income and seropositivity for $T$. gondii. ${ }^{12}$ More seropositivity was found among pregnant women with low socioeconomic status than high socioeconomic. This significant association could be due to pregnant women of low socioeconomic status being more prone to live and work in highly dense areas with poor sanitary conditions and lack good education on good hygienic practice..$^{29,30}$

In this study, a significant interaction was also observed between $T$. gondii seropositivity and occupational status of the study participants. Self-employed (traders) pregnant women were 2.53 times more likely to be seropositive for $T$. gondii compared to governmental employee participants $(p=0.019)$. This finding is in agreement with the study conducted in Nigeria. ${ }^{31}$ In contrast, studies conducted in Tanzania ${ }^{32}$ and Ethiopia ${ }^{16,18}$ reported an insignificant association between occupational status and $T$. gondii seropositivity. The observed difference might be due to variation in the occupational classification of the study participant in this study. Additionally, selfemployed (traders) pregnant women were more at risk to T. gondii seropositivity, probably due to more exposure to contaminated meat, vegetables and fruits, while working as merchants or seller (while working in the cafeteria or restaurants). Moreover, these workers might prefer outing, thus exposed to contaminated feed (undercooked meat, fruit and salad) and water. ${ }^{29}$

The habit of handwashing practice after handling raw meat also showed a significant effect on the seropositivity of pregnant women for $T$. gondii. The odds of being seropositive for $T$. gondii was about two times more likely 


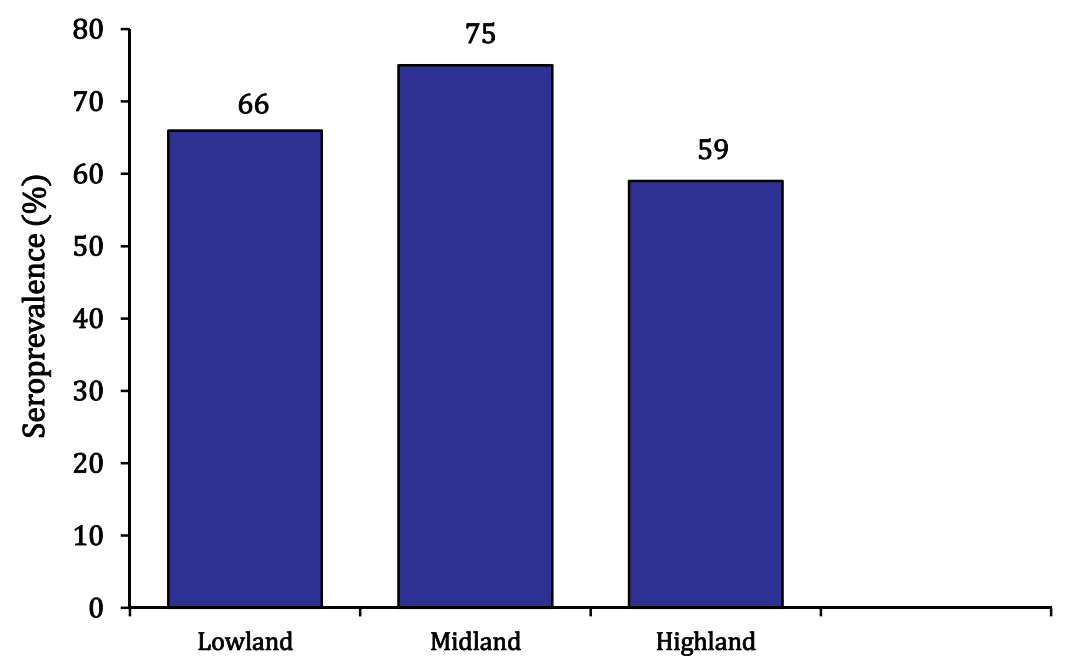

Figure 2 Seroprevalence of $T$. gondii infection in relation with agroecology of residence.

to occur in those who have washed their hands irregularly after handling raw meat than those who always wash their hands after handling raw meat $(\mathrm{AOR}=1.93, p=0.031)$. It is in agreement with the previous study done in Sri Lanka. $^{28}$ In contrast, some studies report the absence of association between $T$. gondii seropositivity and handwashing practice while handling raw meat. ${ }^{18,23}$ This significant association indicates that contaminated or infected raw meat could serve as a source of $T$. gondii infection during handling raw meat for preparation and selling or any purpose due to a high possibility of accidental ingestion of tissue cysts or tachyzoites from animal blood. ${ }^{29}$

A statistically significant association was also documented between the source of drinking water and seropositivity for $T$. gondii. The odds of being seropositive for T. gondii were 2.37 times more likely to be observed in participants who used the unprotected well/spring water source for drinking purposes than those study participants who used the municipal pump water source for drinking $(p<0.05)$. This is in agreement with the previous study conducted. ${ }^{33}$ Contrarily, the absence of a significant association between $T$. gondii seropositivity and water sources used for drinking were reported in other studies. ${ }^{14,15}$ The observed association between $T$. gondii seropositivity and water source in this study indicates that high contamination of wells/spring by $T$. gondii oocysts from cats' faeces and inadequate water management, which could serve as the source of $T$. gondii infection. ${ }^{18}$

Residence agroclimatic situations also showed a significant effect on seropositivity for $T$. gondii in pregnant women in this study. Hence, those study participants who resided in the midland area were about two times more likely to be seropositive than those pregnant women resided in the highland areas $(\mathrm{AOR}=2.16, p=0.007)$. This conforms to the previous study conducted in Ethiopia. ${ }^{12}$ This might be attributed to the difference in the climatic conditions, where higher seropositivity influenced by humidified, moist and wet areas, which are favourable for oocyst sporulation. Oocyst survival also increases and remains viable more than a year in a moist environment that results in high contraction of infection of human and animals. ${ }^{34}$

Cats excrete millions of viable oocysts with their faeces in a short period and play a major role in the transmission of T. gondii. However, the current study showed that the presence of cats at home was not significantly associated with seropositivity for $T$. gondii although the prevalence was high in pregnant women. Similar findings were observed in various countries. ${ }^{16,18,28,35}$ However, this finding is inconsistent with several studies that reported as the owing cat significantly correlated with $T$. gondii seropositivity. ${ }^{11,14,15,36}$ The difference in the types of cats (stray and pet) and infection rates in cats may account for the observed differences. ${ }^{24}$ Alternatively, study participants might acquire infection via different routes such as raw meat and vegetable consumption, contaminated water and from the contaminated environment (soil).

The insignificant interaction was observed between the gestational period and Toxoplasma seropositivity in this study. Corresponding findings were also reported in several studies. ${ }^{16,18,23,24}$ This study also demonstrated that the 
habit of eating raw meat was not significantly associated with T. gondii seropositivity. Similar findings were also reported in other studies. ${ }^{16,23,37}$ In contrast, a significant association between $T$. gondii infection and eating raw/ undercooked meat has been reported. ${ }^{35,38}$ This difference might be due to the frequency of raw meat consumed, the type of animal's meat consumed (cattle, sheep, goat, pig) and the prevalence of the parasite in the animals. ${ }^{23}$ Moreover, this study showed that educational level, history of abortion, history of blood transfusion, the number of gravidities and habits of raw vegetable consumption had an insignificant effect on $T$. gondii seropositivity among pregnant women. This agrees with the report from southern Ethiopia. ${ }^{25}$

In conclusion, the result of this finding revealed high T. gondii seropositivity among pregnant women in the study area. Of the predictors assessed in this study, having an average monthly income, occupational status, altitude, the habit of handwashing practices after handling raw meat and water sources for drinking were found to be important predictors that increase the odds of $T$. gondii seropositivity in pregnant women. Therefore, further studies on bioassay, isolation and genotyping of the pathogen are crucial. It also requires action to avert and control the infection with T. gondii in pregnant women, which poses a potential threat to the foetus.

\section{Acknowledgments}

We would like to thank all volunteer participants to accomplish this work. We would also like to acknowledge the Office of Vice President for Research and Community Service, the University of Gondar for its financial support.

\section{Disclosure}

The authors report no conflict of interest in this work.

\section{References}

1. Bigna JJ, Tochie JN, Tounouga DN, et al. Global, regional, and country seroprevalence of Toxoplasma gondii in pregnant women: a systematic review, modelling and meta-analysis. Sci Rep. 2020;10 (1):12102. doi:10.1038/s41598-020-69078-9

2. Nayeri T, Sarvi S, Moosazadeh M, Amouei A, Hosseininejad Z, Daryani A. The global seroprevalence of anti-Toxoplasma gondii antibodies in women who had spontaneous abortion: a systematic review and meta-analysis. PLoS Negl Trop Dis. 2020;14(3): e0008103. doi:10.1371/journal.pntd.0008103

3. Tarekegn ZS, Dejene H, Addisu A, Dagnachew S. Potential risk factors associated with seropositivity for Toxoplasma gondii among pregnant women and HIV infected individuals in Ethiopia: a systematic review and meta-analysis. PLoS Negl Trop Dis. 2020;14 (12):e0008944. doi:10.1371/journal.pntd.0008944
4. Dubey JP. Toxoplasmosis of Animals and Humans. 2nd ed. Boca Raton, Florida, New York: CRC Press Inc; 2010:1-313.

5. Dubey JP, Tiao N, Gebreyes WA, Jones JL. A review of toxoplasmosis in humans and animals in Ethiopia. Epidemiol Infect. 2012;140 (11):1935-1938. doi:10.1017/S0950268812001392

6. Wang L, Cheng HW, Huang KQ, et al. Toxoplasma gondii prevalence in food animals and rodents in different regions of China: isolation, genotyping and mouse pathogenicity. Parasit Vectors. 2013;6(1):273. doi:10.1186/1756-3305-6-273

7. Odeniran PO, Omolabi KF, Ademola IO. Risk factors associated with seropositivity for Toxoplasma gondii in population-based studies among immunocompromised patients (pregnant women, HIV patients and children) in West African countries, Cameroon and Gabon: a meta-analysis. Acta Trop. 2020;209:105544. doi:10.1016/j. actatropica.2020.105544

8. Cong W, Dong XY, Meng QF, et al. Toxoplasma gondii infection in pregnant women: a Seroprevalence and Case-Control Study in Eastern China. Biomed Res Int. 2015;2015:170278. doi:10.1155/ 2015/170278

9. Boudaouara Y, Aoun K, Maatoug R, Souissi O, Bouratbine A, Abdallah RB. Congenital toxoplasmosis in tunisia: prenatal and neonatal diagnosis and postnatal follow-up of 35 cases. Am J Trop Med Hyg. 2018;98(6):1722-1726. doi:10.4269/ajtmh.17-0580

10. Rostami A, Riahi SM, Gamble HR, et al. Global prevalence of latent toxoplasmosis in pregnant women: a systematic review and meta-analysis. Clin Microbiol Infect. 2020;26(6):673-683. doi:10.10 16/j.cmi.2020.01.008

11. Zemene E, Yewhalaw D, Abera S, Belay T, Samuel A, Zeynudin A. Seroprevalence of Toxoplasma gondii and associated risk factors among pregnant women in Jimma town, Southwestern Ethiopia. BMC Infect Dis. 2012;12(1):337. doi:10.1186/1471-2334-12-337

12. Gebremedhin EZ, Abebe AH, Tessema TS, et al. Seroepidemiology of Toxoplasma gondii infection in women of child-bearing age in central Ethiopia. BMC Infect Dis. 2013;13(1):101. doi:10.1186/14712334-13-101

13. Walle F, Kebede N, Tsegaye A, Kassa T. Seroprevalence and risk factors for Toxoplasmosis in HIV infected and non-infected individuals in Bahir Dar, Northwest Ethiopia. Parasit Vectors. 2013;6 (1):15. doi:10.1186/1756-3305-6-15

14. Agmas B, Tesfaye R, Koye DN. Seroprevalence of Toxoplasma gondii infection and associated risk factors among pregnant women in Debre Tabor, Northwest Ethiopia. BMC Res Notes. 2015;8(1):107. doi:10.1186/s13104-015-1083-2

15. Awoke K, Nibret E, Munshea A. Sero-prevalence and associated risk factors of Toxoplasma gondii infection among pregnant women attending antenatal care at Felege Hiwot Referral Hospital, northwest Ethiopia. Asian Pac J Trop Med. 2015;8(7):549-554. doi:10.1016/j. apjtm.2015.06.014

16. Gelaye W, Kebede T, Hailu A. High prevalence of anti-toxoplasma antibodies and the absence of Toxoplasma gondii infection risk factors among pregnant women attending routine antenatal care in two hospitals of Addis Ababa, Ethiopia. Int $J$ Infect Dis. 2015;34:41-45. doi:10.1016/j.ijid.2015.03.005

17. Tilahun B, Hailu Y, Tilahun G, et al. Seroprevalence and risk factors of Toxoplasma gondii infection in humans in East Hararghe Zone, Ethiopia. Epidemiol Infect. 2016;144(1):64-71. doi:10.1017/S095 0268815001284

18. Negero J, Yohannes M, Woldemichael K, Tegegne D. Seroprevalence and potential risk factors of $\mathrm{T}$. gondii infection in pregnant women attending antenatal care at Bonga Hospital, Southwestern Ethiopia. Int J Infect Dis. 2017;57:44-49. doi:10. 1016/j.ijid.2017.01.013

19. Gebremedhin EZ, Agonafir A, Tessema TS, et al. Seroepidemiological study of ovine toxoplasmosis in East and West Shewa Zones of Oromia Regional State, Central Ethiopia. BMC Vet Res. 2013a;9(1):117. doi:10.1186/1746-6148-9-117 
20. Tegegne D, Kelifa A, Abdurahaman M, Yohannes M. Seroepidemiology and associated risk factors of Toxoplasma gondii in sheep and goats in Southwestern Ethiopia. BMC Vet Res. 2016;12 (1):280. doi:10.1186/s12917-016-0906-2

21. Gebremedhin EZ, Abdurahaman M, Tessema TS, et al. Isolation and genotyping of viable Toxoplasma gondii from sheep and goats in Ethiopia destined for human consumption. Parasit Vectors. 2014;7 (1):425. doi:10.1186/1756-3305-7-425

22. Endris M, Belyhun Y, Moges F, et al. Seroprevalence and associated risk factors of Toxoplasma gondii in pregnant women attending in Northwest Ethiopia. Iran J Parasitol. 2014;9(3):407-414.

23. Abamecha F, Awel H. Seroprevalence and risk factors of Toxoplasma gondii infection in pregnant women following antenatal care at Mizan Aman General Hospital, Bench Maji Zone (BMZ), Ethiopia. BMC Infect Dis. 2016;16(1):460. doi:10.1186/s12879-016-1806-6

24. Yohanes T, Zerdo Z, Chufamo N, Abossie A. Seroprevalence and associated factors of Toxoplasma gondii infection among pregnant women attending in antenatal Clinic of Arba Minch Hospital, South Ethiopia: a cross-sectional study. Transl Biomed. 2017;8(1):105. doi: $10.21767 / 2172-0479.1000105$

25. Jula J, Girones G, Edao B, et al. Seroprevalence of Toxoplasma gondii infection in pregnant women attending antenatal care in southern Ethiopia. Rev Esp Quimioter. 2018;31(4):363-366.

26. Shrestha B, Dunn L. The Declaration of Helsinki on medical research involving human subjects: a Review of Seventh Revision. J Nepal Health Res Counc. 2020;17(4):548-552. doi:10.33314/jnhrc.v1 $7 \mathrm{i} 4.1042$

27. Bamba S, Cissé M, Sangaré I, Zida A, Ouattara S, Guiguemdé RT. Seroprevalence and risk factors of Toxoplasma gondii infection in pregnant women from Bobo Dioulasso, Burkina Faso. BMC Infect Dis. 2017;17(1):482. doi:10.1186/s12879-017-2583-6

28. El-Shqanqery HE, Ibrahim HM, Mohamed AH, El-Sharaawy AA. Seroprevalence of Toxoplasma gondii infection and associated risk factors among asymptomatic pregnant females in Egypt. J Egypt Soc Parasitol. 2017;47(1):93-100.

29. Iddawela D, Vithana S, Ratnayake C. Seroprevalence of toxoplasmosis and risk factors of Toxoplasma gondii infection among pregnan women in Sri Lanka: a cross-sectional study. BMC Public Health. 2017;17(1):930. doi:10.1186/s12889-017-4941-0
30. Frimpong C, Makasa M, Sitali L, Michelo C. Seroprevalence and determinants of toxoplasmosis in pregnant women attending antenatal clinic at the university teaching hospital, Lusaka, Zambia. BMC Infect Dis. 2017;17(1):10. doi:10.1186/s12879-016-2133-7

31. Nasir IA, Aderinsayo AH, Mele HU, Aliyu MM. Prevalence and associated risk factors of Toxoplasma gondii antibodies among pregnant women attending Maiduguri teaching hospital, Nigeria. $J$ Med Sci. 2015;15(3):147. doi:10.3923/jms.2015.147.154

32. Paul E, Kiwelu I, Mmbaga B, et al. Toxoplasma gondii seroprevalence among pregnant women attending antenatal clinic in Northern Tanzania. Trop Med Health. 2018;46(1):39. doi:10.1186/s41182-0180122-9

33. Pratap R, Aslami AN, Sahu NP. Sero-epidemiology of toxoplasmosis and associated risk factors among antenatal women in Ranchi, Jharkhand, India. Int J Res Med Sci. 2016;4:4742-4746. doi:10. 18203/2320-6012.ijrms20163760

34. El-sayed NM, Almannoni SAS. Seroprevalence of Toxoplasma gondii infection and associated risk factors among pregnant women in Sebha region, Libya. Int J Allied Med Sci Clin Res. 2016;4 (3):383-391.

35. Wam EC, Sama LF, Ali IM, Ebile WA, Aghangu LA, Tume CB. Seroprevalence of Toxoplasma gondii IgG and IgM antibodies and associated risk factors in women of child-bearing age in Njinikom, NW Cameroon. BMC Res Notes. 2016;9(1):406. doi:10.1186/s13104016-2206-0

36. Liu Q, Wei F, Gao S, et al. Toxoplasma gondii infection in pregnant women in China. Trans R Soc Trop Med Hyg. 2009;103(2):162-166. doi:10.1016/j.trstmh.2008.07.008

37. Bittencourt LH, Lopes-Mori FM, Mitsuka-Breganó R, et al. Seroepidemiology of toxoplasmosis in pregnant women since the implementation of the Surveillance Program of Toxoplasmosis Acquired in Pregnancy and Congenital in the western region of Paraná, Brazil. Rev Bras Ginecol Obstet. 2012;34(2):63-68.

38. Negash T, Tilahun G, Medhin G. Seroprevalence of Toxoplasma gondii in Nazareth Town, Ethiopia. Cent Afr J Med. 2007;53 (9-12):47-51.
Infection and Drug Resistance

\section{Publish your work in this journal}

Infection and Drug Resistance is an international, peer-reviewed openaccess journal that focuses on the optimal treatment of infection (bacterial, fungal and viral) and the development and institution of preventive strategies to minimize the development and spread of resistance. The journal is specifically concerned with the epidemiology of antibiotic resistance and the mechanisms of resistance development and diffusion in both hospitals and the community. The manuscript management system is completely online and includes a very quick and fair peerreview system, which is all easy to use. Visit http://www.dovepress.com/ testimonials.php to read real quotes from published authors. 